\title{
A CONTINUIDADE ENTRE OS MÉTODOS FORMAIS E INFORMAIS DE DEMONSTRAÇÃO NA PRÁTICA FILOSÓFICA
}

\author{
Nastassja Pugliese ${ }^{1}$
}

\begin{abstract}
RESUMO
O papel da lógica na filosofia é fundamentalmente metodológico já que é fazendo uso das diferentes estruturas de demonstração que teses filosóficas são estabelecidas. Dada a variedade dos modos de apresentação dos textos filosóficos, entendo que para que a tese do papel da lógica na filosofia - em sentido amplo - possa ser defendida, a lógica deve ser tomada sua concepção mais larga, abarcando tanto a lógica formal quanto a informal. Argumento que, mesmo considerando as várias formas de demonstração filosóficas e as diversas relações possíveis entre lógica e filosofia, há uma continuidade entre os métodos formais e informais de demonstração. Para mostrar esta continuidade, partirei da noção fundamental de inferência lógica para estabelecer os critérios de diferenciação entre o formal e o informal, e reconstruirei brevemente a história filosófica da lógica para mostrar suas transformações e seu distanciamento progressivo do lugar metodológico na filosofia. Finalmente, considerando a literatura recente sobre lógica formal e informal, aponto os problemas relativos às suas diferenças e, partindo do reconhecimento de que lógica cumpre um papel metodológico na filosofia, argumento que a lógica formal e informal são práticas que estão em continuidade e se beneficiam mutuamente. No que diz respeito ao modo como a lógica informal se beneficia da lógica formal, o artigo investigará as vantagens e limitações em se tomar os sistemas de dedução natural como instrumento de análise de demonstrações em linguagem natural. No que diz respeito aos modos como a lógica formal pode se beneficiar da lógica informal, procuraremos mostrar que avanços na lógica formal decorrem, além dos esforços de formalização de provas informais, de uma análise informal das estratégias de cálculo e dos princípios segundos os quais uma certa linguagem lógica opera.
\end{abstract}

Palavras-chave: Lógica Formal. Lógica Informal. Método Filosófico. História da Lógica. Inferência. Demonstração.

\footnotetext{
ABSTRACT

The role of logic in philosophy is fundamentally methodological since it is through the usage of different demonstrative structures that philosophical theses are established. Given the variety of modes of presentation of philo-

${ }^{1}$ Professora Adjunta de Filosofia da Educação na Faculdade de Educação da UFRJ e docente permanente do Programa de Pós-Graduação em Lógica e Metafísica do Departamento de Filosofia da UFRJ. E-mail: nastassja.saramago@fe.ufrj.br. ORCID: 0000-0002-1961-3873.
} 
sophical texts, I understand that for the thesis of the methodological role of logic in philosophy - in an encompassing sense - to be defended, logic has to be taken in its most general conception, involving both formal and informal logic. I argue that, even considering the various forms of philosophical demonstration and the various possible relationships between logic and philosophy, there is a continuity between formal and informal methods of demonstration. In order to show this continuity, I will start from the fundamental notion of logical inference to establish criteria for distinguishing between the formal and the informal, and I will briefly reconstruct the philosophical history of logic to show its transformations and its progressive distancing of its methodological role in philosophy. Finally, considering the recent literature on formal and informal logic, I will point out problems with respect to their differences and, from the recognition that logic plays a methodological role in philosophy, I will argue that formal and informal logic are practices that are in continuity and are mutually beneficial. With respect to the way in which informal logic benefits from formal logic, the article will investigate the advantages and the limitations in taking systems of natural deduction as instruments of analysis of demonstrations in natural language. With respect to how formal logic benefits from informal logic, I will show that advances in formal logic depend upon not only efforts for formalising informal proofs, but also from an informal analysis of calculi strategies and from the principles according to which a logical language operates.

Key-words: Formal Logic. Informal Logic. Philosophical Method. History of Logic. Inference. Demonstration.

\section{Introdução}

Em uma investigação sobre a relação entre a lógica formal e informal a partir do lugar da lógica como método na filosofia, é preciso mostrar em que medida o estudo das noções de inferência e validade, das diferentes estratégias de prova e de demonstração se relacionam com a filosofia. Esse passo é importante porque a teoria da prova é motivada pelo estudo das estruturas gerais das provas do modo como elas ocorrem na matemática, mas as questões tratadas em teoria da prova e a própria noção de prova não se limitam e não são circunscritas à sua expressão na matemática. A lógica formal e a teoria da pro$\mathrm{va}^{2}$, por nos oferecem uma teoria sobre noções lógicas, sobre demonstrações,

\footnotetext{
${ }^{2}$ Há diversos modos de estabelecer as relações que aqui estabeleço já que há vários métodos dedutivos disponíveis e, mais importante ainda, várias formas de se fazer filosofia. Neste artigo darei exemplos a partir de desenvolvimentos vindos da teoria da prova e os relacionarei com toda prática filosófica que se proponha demonstrativa. Este trabalho não se propõe discutir o que é ou não é filosófico, isto é, não discute o problema da demarcação. A intenção é mostrar que, nas práticas filosóficas demonstrativas, a lógica cumpre um papel metodológico e que lógica formal e informal estão em continuidade neste tipo
} 
derivações e as propriedades dos sistemas lógicos, elas nos informam também sobre as estruturas gerais dos argumentos e dos sistemas filosóficos. Assim, minha hipótese, neste artigo, é a de que o estudo dos métodos de prova na lógica e sua comparação com as demonstrações informais traz compreensão sobre o modo pelo qual construímos argumentos filosóficos. A lógica formal nos permitirá compreender como as relações de inferência ocorrem no interior de um sistema dedutivo e também, por oposição, como elas se dão fora dele. Assim, compreendendo como a lógica formal sistematiza procedimentos de raciocínio empregados em linguagem natural podemos a partir daí investigar se estas sistematizações se afastam ou mantêm proximidade com os processos de pensamento que ela, de alguma modo, codifica $^{3}$. Este artigo, ao se debruçar sobre as noções de método, prova e demonstração, pretende comparar os procedimentos formais e os não-formais a partir do contexto da prática filosófica. Dado que não é evidente considerar que a lógica formal possa servir de método para a filosofia e esteja, portanto, em continuidade com procedimentos de raciocínio informais realizados em linguagem natural, mostrarei, como a noção de inferência é essencial para todas as noções de demonstração, sejam elas formais ou informais.

A noção de inferência é central para a demonstração filosófica, pois ela se encontra presente em todo e qualquer processo de raciocínio, seja ele um procedimento lógico formal ou informal. Há diferentes formas de inferência, mas para nossos fins precisamos apenas diferenciar entre consequência lógica (que é uma inferência num contexto dedutivo) e as inferências em geral (que ocorrem em contextos dedutivos ou não-dedutivos). A partir da idéia de que há inferências dedutivas e não-dedutivas, podemos também esclarecer o que entendemos como prova e como demonstração. De modo análogo, partimos do princípio de que a prova é diferente da demonstração na medida em que a prova é oferecida e realizada dentro de um contexto de dedução e as de-

\footnotetext{
de prática.

3 Como mostra Shapiro (1998), “um slogan comum é o de que a lógica codifica normas pré-teóricas do raciocínio correto, como a noção de consequência lógica. Este slogan é certamente correto, dentro de suas limitações, mas ele também é certamente limitado. O que é esta noção pré-teórica de consequência lógica e o que quer dizer codificar alguma coisa?" (Shapiro 1998, p. 1). Em uma pesquisa futura procurarei investigar estas questões, mas aqui me limitarei ao problema da relação entre a lógica formal e a lógica informal.
} 
monstrações podem vir a ocorrer também em contextos não-dedutivos. Assim, do mesmo modo, a noção de inferência é relacionada com a noção de consequência lógica, a demonstração é um conceito mais geral que inclui o conceito de prova, mas não se reduz a ele. Finalmente, consideraremos como método, certos procedimentos ordenados ou sistematizados para a realização de provas ou demonstrações a partir da análise, construção ou cálculo de inferências. Nossa investigação parte, portanto, dessas distinções fundamentais.

\section{Inferência como conceito lógico-filosófico fundamental}

Comecemos, portanto, analisando como a noção de consequência lógica, a versão forte da inferência, serve de fio condutor para o estudo da continuidade entre lógica formal e informal ${ }^{4}$. Griffiths (2014), no artigo "Formal and Informal Consequence”, mostra que a definição padrão de consequência lógica é originária da teoria de modelos, mas chama atenção para o fato de que há, ao menos duas noções formais de consequência lógica: uma vinda da teoria de modelos e outra da teoria da prova ${ }^{5}$. Elas são as seguintes:

(def. teoria de modelos): uma sentença $\phi$ é consequência lógica de um conjunto de sentenças $\Gamma$ sse todo modelo de $\Gamma$ é um modelo de $\phi$.

\footnotetext{
${ }^{4}$ Shapiro (1998) aponta que há várias questões a serem investigadas a respeito da noção de consequência lógica no contexto da teoria de modelos. Dentre elas estão: questões sobre as relações entre as linguagens formais e as linguagens naturais, questões sobre a natureza da forma lógica, questões sobre as diferenças entre os termos na lógica e estes mesmos termos utilizados de forma não-lógica e, ainda, questões epistemológicas e metafísicas. Neste trabalho, trataremos da noção de inferência e como ela serve de fio condutor para analisar as semelhanças entre lógica formal e informal. Enquanto na lógica formal a inferência torna-se consequência lógica, na lógica informal, temos uma noção de inferência mais fraca, que é a noção informal de consequência.

${ }^{5}$ Tomamos este artigo de Griffths (2014) como base porque ele oferece definições de consequência lógica que colabora para nossos fins. Importante deixar claro que a literatura em filosofia da consequência lógica é extensa e inclui desenvolvimentos complexos tanto em teoria do significado (ex. Dummet 1991) na construção de sistemas lógicos (Shoesmith \& Smiley 1978, Brandon 1994). Os autores mais tradicionais para as discussões sobre o tema no contexto da lógica moderna são Bolzano e seu conceito de dedutibilidade lógica (1837) e Tarksi (1986). Sabemos, no entanto, que a noção de consequência lógica é preocupação comum entre todos os filósofos que contribuíram direta ou indiretamente para a história da lógica. Neste artigo, além destas duas noções de consequência lógica, ainda consideramos que há uma versão fraca da noção de consequência, instrumentalizada na lógica informal, e que captura nossa noção pré-teórica de inferência não-dedutiva. É a partir desta noção de informal de inferência que mostraremos a continuidade entre lógica formal e lógica informal.
} 
(def. teoria da prova): uma sentença $\phi$ é consequência lógica de um conjunto de sentenças $\Gamma$ sse $\phi$ for dedutível de $\Gamma$ usando as regra de um sistema de prova padrão para a lógica de primeira ordem.

A primeira definição formal de consequência lógica é semântica enquanto a segunda é sintática, mas ambas capturam o seguinte resultado: se as sentenças de $\Gamma$ forem tomadas como as premissas de um argumento e $\phi$ como a conclusão deste argumento, temos que, se $\phi$ for consequência lógica de $\Gamma$, então podemos dizer que o argumento é dedutivamente válido e sólido. Assim, tomando conjuntamente estas definições de consequência lógica, podemos compreender porque o "bom argumento" é considerado como aquele que é válido e sólido. O "bom argumento" é válido e sólido porque, dada sua forma, nele a conclusão segue das premissas de modo que ela é consequência lógica das premissas, ou seja, é impossível que, se as premissas forem verdadeiras, a conclusão seja falsa. Dizer que $\Gamma$ tem modelo, é dizer que há ao menos uma interpretação possível na qual todas as sentenças de $\Gamma$ são verdadeiras. Assim, dizer que $\phi$ é consequência lógica de $\Gamma$ sse todo modelo de $\Gamma$ é um modelo de $\phi$, quer dizer que se todas as sentenças de $\Gamma$ forem verdadeiras em determinado modelo, então $\phi$ também será verdadeiro neste modelo. Dizer, por outro lado, que de $\Gamma$ deduz-se $\phi$ a partir de um sistema de prova padrão, é dizer que, neste sistema, $\phi$ é derivável do conjunto de sentenças $\Gamma$. Assim, tomando $\Gamma$ e $\phi$ como partes de um argumento, dizer que $\phi$ é derivável do conjunto de sentenças $\Gamma$, é o mesmo que dizer que o argumento é válido; e dizer que há um modelo no qual tanto as sentenças de $\Gamma$ quanto $\phi$ são verdadeiros ao mesmo tempo, é dizer que o argumento é sólido. Deste modo, vemos que as definições formais de consequência lógica vindas da teoria de modelos e da teoria da prova explicam certas propriedades dos argumentos.

Argumentos, entretanto, não se restringem a este formato onde a conclusão é consequência lógica das premissas. Argumentos, de um modo mais geral, são conjuntos de sentenças nos quais algumas são premissas e uma outra é a conclusão. Um argumento bem formado é aquele cuja conclusão se segue ou provavelmente se segue das premissas. Quando dizemos que a 
conclusão segue das premissas, dizemos que é possível inferir a verdade da conclusão a partir da assunção de que as premissas são verdadeiras. Quando a verdade da conclusão necessariamente segue da verdade das premissas, temos um argumento dedutivo onde a conclusão é consequência lógica das premissas. Nos casos em que a verdade da conclusão de um argumento é apenas provável dada a verdade das premissas, não podemos mais dizer que a conclusão é consequência lógica das premissas. No entanto, dado um argumento bem formado, há, necessariamente, uma relação de implicação entre as premissas e a conclusão. Essa relação de implicação é chamada, como apontamos acima, de relação de inferência.

Assim, de um modo mais abrangente, podemos retomar a definição de argumento e recolocá-lo do seguinte modo: um argumento é um conjunto de sentenças no qual algumas destas sentenças são premissas, uma delas é a conclusão, de modo que há uma relação de inferência entre as premissas e a conclusão. Ao se incluir, de modo explícito, a noção de inferência na definição de argumento, torna-se possível categorizar argumentos de acordo com os diferentes graus de necessidade com os quais a verdade da conclusão se segue as verdades das premissas. Como vimos nas definições, a consequência lógica é uma versão forte da inferência. Em um argumento dedutivo cuja conclusão é consequência lógica das premissas, a conclusão pode ser deduzida da verdade das premissas a partir de um procedimento de prova (no caso, demonstrado através de uma derivação). Isto porque, neste caso, a verdade da conclusão segue necessariamente da verdade das premissas. A relação de inferência mais fraca é aquela na qual a conclusão é provavelmente verdadeira e há um certo risco em concluir a verdade da conclusão segue-se da verdade das premissas. Assim, temos que a relação de inferência é mais abrangente que a relação de consequência lógica, já que a consequência lógica é um tipo de relação de inferência mas nem toda relação de inferência é uma consequência lógica. E, neste último caso, no caso dos argumentos não-dedutivos, ainda que possamos demonstrar que a verdade da conclusão provavelmente se segue da verdade das premissas, não é possível fazer uso de procedimentos de prova para realizar esta demonstração. Esta demonstração deve ser feita de modo informal, a 
partir da enumeração de razões que justifiquem a cogência de tal argumento, por apelo às noções comuns ou às ferramentas da teoria de probabilidades.

Estas distinções nos servem para que possamos observar como há uma diferença de grau entre os tipos de inferência e que é correto dizer que, assim como a consequência lógica é a forma mais forte de inferência, o argumento dedutivamente válido é a forma mais forte de um argumento. Outra consequência destas diferenças entre os tipos de relação de inferências que definem as formas dos argumentos é que deve haver um método de demonstração distinto para cada forma de argumento. O método para demonstrar que a conclusão de um argumento dedutivamente válido segue-se da verdade de suas premissas não é e não pode ser o mesmo que o método utilizado para demonstrar que a conclusão de um argumento não-dedutivo provavelmente segue-se da verdade das suas premissas. Assim, para uma compreensão e um estudo mais detalhado das dimensões metodológicas da lógica na filosofia, é preciso analisar as diferenças entre as diferentes propriedades dos argumentos, os diferentes métodos de demonstração e os vários graus de certeza das inferências. Vejamos como essas noções e estas diferenças foram operadas ao longo da história e marcaram o movimento de abstração crescente em lógica.

\section{Breves considerações históricas e a lógica como método}

A conclusão a qual chegamos, de que há diferentes graus de certeza nas relações de inferência, onde a consequência lógica é o tipo de inferência mais forte (dado que é dedutiva) está de acordo com (e de certo modo repete) o que Aristóteles argumenta nos Segundos Analíticos. Nele, Aristóteles defende que há apenas um tipo de demonstração, entre várias, que deve contar como uma demonstração verdadeiramente científica. A demonstração que, para Aristóteles, funciona como uma prova, ocorre apenas quando apresentamos um argumento na forma do mais forte dentre todos os silogismos possíveis. Aristóteles argumenta que há, entre os silogismos válidos, o mais seguro deles. Este "silogismo entre os silogismos" é chamado, posteriormente, de de- 
monstração potissima ${ }^{6}$ e só ela é considerada como uma demonstração verdadeiramente científica. Uma demonstração potissima é um argumento válido que tem a forma de um silogismo de primeira figura com premissas universais, mais conhecidas e anteriores que a conclusão. A conclusão desde silogismo, por sua vez, também é universal e está relacionada com as premissas do mesmo modo com que efeitos se relacionam com causas. Aristóteles estabelece que uma demonstração, para ser científica, deve observar certos requerimentos precisos. Importante deixar claro que estes requerimentos exigem muito mais do que a presença de uma relação de consequência lógica entre as premissas e conclusão de um argumento: a verdade das premissas de uma demonstração potissima deve ser imediata, primeira e anterior, ou seja, devemos conhecer a verdade das premissas antes e melhor do que a conclusão, e as premissas devem ser sobre as causas que explicam um certo efeito sobre o qual versa a conclusão. Já que para Aristóteles, conhecer é conhecer pelas causas (aitia), o conhecimento científico deve ser obtido pela demonstração da relação entre causa e efeito. Com estes requerimentos fortes, Aristóteles dá os primeiros passos na direção do uso da lógica como método de demonstração científica (ou como método de prova) ${ }^{7}$. Aristóteles, apontando as diferenças entre o raciocínio científico e o raciocínio retórico, e entre os diversos tipos de silogismos, nos indica que para fazermos ciência (e filosofia) precisamos analisar as diferentes propriedades dos argumentos. Estas caracterizações dadas por Aristóteles nos permitem compreender como a defi-

\footnotetext{
${ }^{6}$ A silogística como teoria da investigação e da demonstração manteve-se, durante séculos, como o método mais seguro para as práticas científicas e matemáticas. Na escolástica, comentadores de Aristóteles argumentavam que as ciências mais exatas, como a matemática, eram exatas porque suas demonstrações estavam em conformidade com a definição de ciência perfeita de Aristóteles. Ou seja, tinham suas verdades demonstradas por silogismos demonstrativos. Este tipo de demonstração entre as demonstrações, ou este silogismo entre os silogismos, foi chamado por Piccolomini, no século XVI, de demonstração potissimae (Barbara). Piccolomini reconhece que a teoria de Aristóteles, de todo modo, ofereceu as categorias conceituas que permitiram a análise do discurso científico, matemático e lógico. Entretanto, na transição do século XVI para o século XVII, a concepção de ciência de Aristóteles é questionada em um movimento chamado quaestio certitudine mathematicarum (Mancosu 1996). As críticas à Aristóteles e a constatação da impossibilidade de se realizar demonstrações potissimae em todas as áreas da matemática e do saber, levaram à construção de novos métodos de investigação, justificação e demonstração. Nesta esteira de desenvolvimento, se insere o esforço de Leibniz, por exemplo, pela algebrização das demonstrações. A lógica moderna, portanto, pode ser compreendida por suas semelhanças e diferenças em relação à Aristóteles e sua teoria da investigação e da demonstração.

${ }^{7}$ A motivação por trás do estabelecimento do sistema lógico de Aristóteles e sua teoria do silogismo é compreender e realizar demonstrações (apodeixis), ou seja, "deduções que produzem conhecimento". A noção de demonstração em Aristóteles e a teoria dos silogismos funcionam como prelúdio metodológico de sua filosofia.
} 
nição de propriedades e noções lógicas nos permitem codificar noções preteóricas e sistematizar métodos de demonstração. De um modo mais geral, as distinções de Aristóteles também nos auxiliam a compreender os desenvolvimentos metodológicos na história da filosofia e sua relação com os avanços da lógica. Com Aristóteles, vemos que a busca pelas melhores estratégias de demonstração é um esforço que se confunde, em um certo sentido, com o começo da filosofia ${ }^{8}$.

É importante salientar que Aristóteles concebe não só as propriedades e noções lógicas fundamentais, mas também a primeira sistematização de procedimentos de demonstração ao categorizar as formas válidos dos silogismos. A lógica e a teoria do silogismo de Aristóteles foram tão importantes que, por séculos, tornaram-se a grande referência para as práticas científicas e matemáticas. A força do sistema lógico aristotélico é tanta que Kant, ao descrever um momento na história anterior às transformações da lógica matemática no século XIX, concluiu que Aristóteles descobriu tudo o que havia para ser descoberto em lógica e que não havia mais desenvolvimento possível para além da lógica aristotélica. Kant realiza essa leitura mesmo depois da ocorrência das querelas matemáticas do final do século XVI, início do século XVII e os avanços na lógica matemática por parte de Leibniz. Na tradição escolástica, comentadores de Aristóteles argumentavam que as matemáticas eram tidas como ciências exatas porque suas demonstrações estavam em conformidade com a definição de ciência perfeita de Aristóteles. No século XVII, as obras da matemática clássica começaram a ter seus resultados, antes considerados absolutamente certos, questionados. Piccolomini, por exemplo, procura mostrar que as demonstrações matemáticas não podem ser demonstrações potissima porque as relações matemáticas não podem ser pensadas em termos causais. De todo modo, como afirma Mancosu, "a concepção aristotélica de ciência ofereceu as categorias conceituais que permitiram a análise do discurso matemático no começo do século XVII" (Mancosu 1996

\footnotetext{
${ }^{8}$ Como nos mostra Kneale \& Kneale (2008, p. 23), "apesar da palavra 'lógica' ter encontrado seu significado moderno apenas 500 anos depois quando foi utilizada por Alexandre de Afrodísias, o escopo do estudo depois chamado de lógica foi determinado pelo conteúdo do Órganon" [de Aristóteles]. Como vimos, Aristóteles desenvolveu sua lógica com o objetivo apresentá-la como um órganon do conhecimento, ou seja, como um método seguro a partir do qual podemos construir demonstrações científicas.
} 
p.10). O rápido desenvolvimento e o esforço de algebrização das matemáticas mudaram tanto a cara da matemática como da lógica e da filosofia. No século XVII, a influência do método matemático, inspirado na sistematização iniciada com a lógica aristotélica, se fez valer em outras disciplinas como a filosofia, a teologia e a filosofia natural.

O século XVII é a época onde se vê de modo mais evidente a influência do método lógico-matemático na filosofia. Com isto, não queremos dizer apenas que houve uma multiplicação das aplicações de técnicas lógico-matemáticas em certas áreas de estudo específicas (como fez Galileu na matematização da mecânica e Descartes na algebrização da geometria; cf. Mancosu 1996), mas que a matemática é tomada como exemplo de ciência segura. Entendida como um exercício de clareza, ordem, simplicidade, o método lógicomatemático era utilizado para dar segurança e certeza às investigações de diversas áreas do conhecimento. Na filosofia, o caso mais emblemático é o de Espinosa ao escrever uma ética (a partir de seu sistema metafísico) demonstrada à maneira dos geômetras. Neste esforço pela matematização das ciências, o lugar da lógica aristotélica começa a ser questionado até que, com os desenvolvimentos da lógica moderna no século XIX, a teoria dos silogismos é praticamente abandonada'. Entretanto, Smith (2017) nos lembra que

durante o avanço da lógica formal moderna com Frege e Pierce, aqueles que aderiam à lógica tradicional (que viam a si mesmos como descendentes da lógica aristotélica) e aqueles que aderiam à nova lógica matemática viam-se como rivais que defendiam noções incompatíveis de lógica. Pesquisas mais recentes, entretanto, aplicam várias técnicas da lógica matemática às teorias de Aristóteles revelando (na opinião de muitos) um grande número de semelhança de abordagem e de interesse entre Aristóteles e os lógicos modernos. (Smith 2017)

Entretanto, do mesmo modo que hoje podemos ver as semelhanças de abordagem e interesse entre a lógica aristotélica e a moderna a partir da perspectiva da lógica atual, podemos também investigar os pressupostos da lógica moderna a partir de sua dimensão metodológica ou propedêutica na filosofia.

\footnotetext{
${ }^{9}$ Como aponta Mancosu (1996), há duas vertentes explicativas da relação entre a lógica aristotélica e os desenvolvimentos que se iniciam no século XVII e culminam no XIX com a lógica moderna: a perspectiva da continuidade (Crombie 1959, Randal 1961, Von Wright 1971) e a da descontinuidade (McMullin 1965, Gilbert 1963). Em algum momento futuro, a presente pesquisa se debruçará sobre este tema. Mas esta não é a nossa preocupação presente.
} 
Ou seja, acreditamos que podemos (e devemos) analisar a lógica moderna como sendo (ainda) parte da dimensão metodológica da filosofia. Isto porque a lógica moderna nos informa sobre estruturas de argumentos e demonstrações utilizadas no processo de conhecimento ainda que ela tenha se voltado a estratégias de cálculo que independem do processo de conhecimento filosófico.

Esta busca por compreender o lugar da lógica moderna na metodologia filosófica se confunde com as motivações de Aristóteles para construir sua lógica porque quando ele concebe uma ciência dedutiva a partir de certas definições iniciais, sua meta fundamental "não é um guia prático para a argumentação, mas o estudo das propriedades dos sistemas de inferência” (Smith 2017). Este estudo meta-teórico sobre a lógica permite à Aristóteles explorar as relações entre demonstração e conhecimento, entre inferência e verdade, fazendo uso da lógica como método próprio para a ciência e como instrumento da filosofia. Com o surgimento da lógica moderna, voltada para a matemática, perde-se a evidência da relação fundamental que existe entre lógica e as diversas ciências. Neste artigo tomamos a lógica a partir destas relações e nosso interesse é, portanto, tanto no aspecto prático quanto no aspecto histórico da lógica. A história da lógica permite que tenhamos a visão de conjunto necessária para a análise das práticas atuais da lógica formal e para que possamos investigar suas possibilidades metodológicas no ensino de filosofia. Deste modo, é importante lembrar os marcos fundadores da lógica moderna (lógica simbólica ou lógica matemática) e as transformações que ela sofreu nos últimos séculos.

Acreditamos que a lógica moderna cumpre uma função metodológica não apenas por oferecer uma teoria dos argumentos válidos com mais poder expressivo que a de Aristóteles, mas também por nos fornecer uma compreensão sobre o cálculo como operação fundamental do pensamento (GrattanGuinness 2004). A lógica formal moderna, também chamada de lógica simbólica ou lógica matemática, surge no século XIX como um desenvolvimento a partir da matemática tradicional e de sistemas lógicos anteriores ${ }^{10}$. Sabemos

\footnotetext{
${ }^{10}$ A lógica aristotélica foi abandonada em suas pressuposições metafísicas e epistemológicas, mas não em sua estrutura. As formas de inferência válidas na lógica aristotélica, aparecem na lógica formal moderna como casos especiais, ou seja, com um subconjunto de formais mais gerais do raciocínio.
} 
que a lógica formal, ou a lógica simbólica, realiza importantes avanços frente à lógica aristotélica na medida em que ela encontra um modo de tratar tanto de quantidades quanto de estruturas relacionais de alto grau de complexidade. O desenvolvimento da lógica formal se deve, principalmente, ao trabalho de Boole e de Frege. Boole, no The Mathematical Analysis of Logic (1847), construiu um sistema de cálculo inspirado em técnicas da álgebra capaz de formalizar as regras da silogística tradicional. Esta monografia foi fundamental porque nela Boole foi bem sucedido em mostrar que as as operações da lógica aristotélica são análogas às operações algébricas. Esta semelhança entre o raciocínio o lógico e o cálculo aritmético já tinham sido exploradas por Leibniz, que tinha a intenção de construir um método mecânico para a análise de argumentos. Leibniz procurou explorar as analogias existentes entre a operação algébrica da adição e a operação lógica da conjunção (Esquisabel 2012, Casanave 2012). Mas, ao fazê-lo, Leibniz concluiu que esta forma de compreender a lógica como fundada em operações análogas às da álgebra encontra limitações: quando representamos, por exemplo, a conjunção pelo sinal de adição, chegamos à falsidades algébricas (como $\mathrm{A}+\mathrm{A}=\mathrm{A}$ ) e limitamos as possibilidades de combinações das operações lógicas. A estratégia de Boole possui limitações semelhantes, mas, ainda assim, ele realizou um avanço significativo na lógica formal ao construir um algoritmo em linguagem algébrica possível de ser aplicado a uma variedade de argumentos de diferentes níveis de complexidade. Até então, o método tradicional, baseado nas estratégias de Aristóteles, se resumia à catalogação das forma de silogismo válido em suas formas mais simples. Boole desenvolveu um cálculo de operadores de classes capaz de representar algebricamente as formas dos silogismos válidos, tomando os símbolos da álgebra como representações de operações lógicas ${ }^{11}$. Boole então mostrou as vantagens de se investigar as semelhanças entre a lógica e matemática, trazendo novamente a questão filosófica sobre a relação entre a lógica e ontologia. Isto porque, se a lógica e a matemática compartilham de operações fundamentais, então é possível que as leis lógicas se jam também as

\footnotetext{
${ }^{11}$ Como mostra Ewald (2007), o sistema de Boole, entretanto, não permitia operar com relações para além daquelas existentes entre sujeito e predicado em uma proposição e também não possuía quantificadores.
} 
leis do pensamento. Assim, os avanços algébricos na lógica moderna retoma questões fundamentalmente filosóficas como, por exemplo, o estudo sobre os comprometimentos ontológicos (ou ausência deles) subjacentes aos sistemas lógicos.

O segundo grande avanço que constitui a virada matemática na lógica foi realizado por Frege (Grattan-Guiness 2004). Frege construiu o primeiro sistema formal capaz de realizar cálculos de predicados em sentenças quantificadas. Zalta (2017) caracteriza o avanço realizado por Frege como "o desenvolvimento de um método mais perspícuo de representar formalmente a lógica de pensamentos e inferências" fornecendo, deste modo, os fundamentos da lógica moderna. Frege não só construiu um sistema formal capaz de analisar sentenças complexas e quantificadas, mas ofereceu também, como fundamentação teórica, uma teoria da prova e da definição. O cálculo de predicados de Frege é um sistema formal, incluindo uma linguagem formal e um método de prova, no qual podemos representar inferências válidas que ocorrem entre sentenças nas quais propriedades são predicadas de objetos (Zalta 2017). A formulação de Frege é muito próxima do cálculo de predicados moderno ${ }^{12}$. Se tomamos uma sentença e substituímos um nome completo que aparece na sentença por um marcador de lugar, então temos como resultado uma expressão incompleta ou um conceito. Um conceito para Frege é um certo tipo de função que mapeia qualquer argumento em um valor de verdade (verdadeiro ou falso). Por exemplo, a sentença ‘ 4 é par' deve ser formalmente representada como $\mathrm{P}(4)$, onde o predicado 'é par' é analisado como denotando o conceito $\mathrm{P}$ ( ) tal que $\mathrm{P}$ ( ) relaciona todos os números pares com o verdadeiro e todos os outros como falso. A predicação '4 é par' é analisada por Frege como se ela fosse uma função onde 'é par' é o conceito e ‘4' é o argumento. Assim, o sistema de Frege permitiu a análise de predicados não-matemáticos como "é vermelho" ou "é verde". Frege considera que sua lógica fornece todos os princípios para realização de provas dedutivas. Como expresso na Begriffsshrift: "Tudo o que é necessário para a realização de uma inferência correta é completamente expressado, mas o que não é necessário geralmente não está

\footnotetext{
${ }^{12} \mathrm{Na}$ lógica de Frege todos as expressões completas são termos que denotam e, por isso, sua lógica é chamada também de lógica de termos.
} 
indicado; nada é deixado para ser adivinhado" (Frege 1879 p.3) ${ }^{13}$. Assim, enquanto Aristóteles ofereceu um método de combinação de formas válidas previamente categorizadas, Frege concebeu um sistema fechado e finito de regras capaz de funcionar como um algoritmo para a análise de uma quantidade infinita de argumentos válidos com diferentes níveis de complexidade. Dos Santos resume a caracterização de lógica feita no Nachgelassene Schriften (1969 pp. 3 e p. 190) por Frege do seguinte modo: “A tarefa específica da lógica pode ser caracterizada (...) como a de estabelecer sistematicamente leis aptas a medir a legitimidade de conclusões (Schlüsse) ou demonstrações (Beweise)"14. O sistema de Frege permitiu a manipulação de um conjunto de fórmulas consistentes em uma dada linguagem de modo que, sob um ponto de vista meramente combinatório, fossem produzidas derivações de uma dada fórmula a partir de outras fórmulas assumidas como axiomas ou mesmo como meras hipóteses $^{15}$.

\section{Sobre a lógica informal e sua relação com a lógica formal}

A motivação por trás desta breve reconstrução histórica é mostrar que o desenvolvimento da lógica pode ser lido como um esforço, cada vez mais complexo, de formalização de procedimentos de inferência que realizamos quando raciocinamos ${ }^{16}$. Este fato nos permite observar a relação frutífera existente entre demonstrações formalizadas e não-formalizadas e a necessidade de se estudá-las a partir de uma perspectiva de continuidade entre estes esforços.

\footnotetext{
13 A lógica de Frege também inclui a análise de conceitos. Neste artigo não nos debruçaremos sobre esse aspecto da lógica fregeana (como também não nos debruçamos sobre a teoria das definições de Aristóteles), apesar de reconhecermos que este aspecto da lógica, enquanto análise conceitual, é de suma importância para a filosofia.

${ }^{14}$ Dos Santos, Luiz Henrique Lopes. O Olho e o Microscópio. Nau Editora. Rio de Janeiro, 2008. p.23

15 Esta realização inspirou o artigo de Hilbert de formalização da matemática a partir da escolha inicial de certos axiomas. Este artigo de fundamentação da matemática na lógica motivou diversos avanços, mas a demonstração, por Gödel, de sua impossibilidade gerou a crise que está na base do desenvolvimento da teoria da prova do começo do século XX.

${ }^{16}$ Importante salientar as limitações desta reconstrução tanto no que diz respeito às caracterizações das descontinuidades nos desenvolvimentos da lógica quanto no que concerne às contribuições feitas por mulheres e autores não-canônicos à história da lógica. Em pesquisas futuras, a serem publicadas (Pugliese \& Secco no prelo), procurarei apontar os problemas com estes tipos de narrativas históricas nas quais, com este presente trabalho, eu mesma me incluo. Há investigações importantes (e demoradas) a serem feitas nesta direção, como por exemplo, a análise do modo com a história da lógica é apresentada em livros didáticos em Português. Começamos a realizar este tipo de investigação em Secco \& Pugliese (2016), mas há muito o que ser investigado ainda.
} 
A meta mais ampla desta investigação e que não se resolverá neste breve artigo é de investigar como a noção de prova, enquanto ferramenta de análise de sistemas axiomáticos, pode informar e auxiliar a análise de teorias filosóficas não-axiomáticas e não-axiomatizáveis. Ou seja, este é um estudo propedêutico para que posteriormente continuemos a avaliar a possibilidade de se tomar os princípios da prova, como a explicitação de regras de inferência e a escolha de axiomas, como instrumentos para a avaliação de argumentos de diversos tipos (dedutivos e não dedutivos). Para mostrar a interseção entre lógica formal e a prática de argumentação filosófica, nos deteremos agora sobre a lógica informal.

A lógica informal, considerada como em oposição à lógica formal, não parece ter uma prática ou metodologia bem definida. Isto porque, enquanto a lógica formal realiza estratégias mecânicas para a análise de argumentos dedutivamente válidos, a lógica informal cumpre um papel de sistematização e análise, mas de um modo não-mecânico. Entretanto, só encontramos dificuldade em definir a lógica informal se a pensarmos como um substituto da lógica formal. Considerada a partir desta oposição, a lógica informal não passa de uma lógica formal mal feita ${ }^{17}$, utilizando os princípios da dedução da lógica tradicional para operar sobre argumentos não-dedutivos. Segundo estes princípios, os argumentos dedutivamente válidos são os únicos bons argumentos e a inferência mais genuína é a realizada por dedução. Nesta perspectiva dedutivista da lógica informal (Groarke 1999), privilegia-se a estratégia de traduçãocálculo para a manipulação e análise de argumentos, na qual todo e qualquer argumento deve ser transformado em um outro, semelhante ao original, mas que tenha a forma de um argumento dedutivamente válido para que então se realize a análise de inferências. Entretanto, este privilégio da estratégica de tradução-cálculo limita as potencialidades metodológicas da lógica informal e suas possíveis formas de interação tanto com a lógica formal quanto com a linguagem natural para fins de análise de argumentos e modos de inferência.

\footnotetext{
${ }^{17}$ Como diz Fogelin (1999), a lógica informal não passa de uma "informal formal logic" quando ela é concebida a partir do que ele chama de "preconceitos dedutivistas". Aqui não trataremos de preconceitos dedutivistas, mas de uma visão dedutivista que desafia o bom funcionamento da lógica informal.
} 
Para mostrar que a perspectiva da oposição ente lógica formal e informal não é a forma mais fértil de abordar estas práticas e suas relações com a filosofia, apontarei o problema da definição da lógica informal (Hintikka 1989) para então descrever o método informal de análise lógica de argumentos mais adotado (Feldman 1999, Hughes et al 2015, Bonevac 1999, Morrow \& Weston 2011). A partir deste método de análise de argumentos na lógica informal, bem como os princípios que guiam a análise e a busca por padrões de argumentos não-dedutivos que estruturam esta prática, argumentarei que a lógica informal cumpre um papel distinto do da lógica formal. Assim, a partir do estudo desta prática geral de análise de argumentos, mostrarei que a lógica informal não é oposta à lógica formal, mas está em necessária continuidade com ela. Esta compreensão da lógica informal permite a abordagem complementar (Johnson 1999) de ambas as disciplinas de modo que uma se beneficie das práticas da outra, sem que haja conflito de metodologias e confusão de escopo.

As controvérsias entorno da chamada "lógica informal" se justificam porque a lógica informal, por não oferecer um modelo para dar conta de demonstrações e inferências através de regras e procedimentos dedutivos, não é exatamente uma lógica ${ }^{18}$. Ao mesmo tempo, a lógica informal constrói e categoriza procedimentos alternativos de demonstração e inferência na tentativa de sistematizá-los, não sendo, portanto, exatamente um esforço "informal" 19 . Ou seja, as dificuldades entorno da lógica informal existem porque ela não é nem exatamente uma lógica e nem um procedimento não sistematizado ("informal"), sendo um termo genérico o bastante para causar incômodo nos mais diferentes contextos. Hintikka, por exemplo, no artigo "The Role of Logic in Argumentation", de 1989, parte do princípio de que expressão "informal logic" é um solecismo, uma cacologia, um oxímoro e defende a tese forte de que não há nenhuma teoria geral, respeitável, sobre a argumentação infor-

\footnotetext{
18 O conceito de lógica é central aqui dado que o argumento dependente de uma certa concepção de lógica. Ainda que seja possível e, quiçá, inclusive necessário, definir a lógica de modo mais amplo, no presente contexto, por lógica entendo a lógica formal como cálculo proposicional e o cálculo de predicados de primeira e segunda ordem. Ou seja, como a tradicional lógica clássica.

19 Novamente, aqui entendo informal em um sentido estritamente não-técnico, ou seja, enquanto uma prática não-regimentada e sem regras de funcionamento explícitas.
} 
$\mathrm{mal}^{20}$. Hintikka argumenta pela impossibilidade da lógica informal, pois exige que, para ser uma empreitada bem-sucedida, a lógica informal deve oferecer uma teoria da inferência que não seja limitada à inferência dedutiva mas que a inclua, de modo que a lógica informal possa, então, servir de substituto para a lógica formal. Ou seja, ou a lógica informal oferece uma teoria da inferência e uma metodologia de análise da mesma mais forte do que a teoria da inferência dedutiva e os procedimentos da lógica formal, ou ela não vale nada ${ }^{21}$.

Tal expectativa é compreensível na medida em que defender o emprego de qualquer procedimento alternativo às estratégias de tradução e cálculo só se justifica se tais procedimentos tiverem um alcance igual ou maior que, por exemplo, os da lógica tradicional. As fraquezas da lógica informal, segundo Hintikka, são três. Nesta proposta de uma "teoria da inferência mais substancial": (1) não estão bem-definidas quais tipos evidências nos levam a realizar inferências não-dedutivas e quais as outras estratégias empregamos face a estas evidências; (2) não se apresentam explicações sobre os elementos que fazem da concepção tradicional de lógica uma boa teoria geral do raciocínio; (3) e, apela-se para critérios como escolher "a melhor explicação entre as possíveis", o que é um critério vago e fraco para sustentar qualquer teoria genuína. Entretanto, a não ser a segunda, estas alegadas fraquezas fazem parte da natureza dos argumentos tratados pela lógica informal e são os desafios mesmos que qualquer teoria sobre argumentos não-dedutivos deve propor-se enfrentar.

Gostaria de mostrar que o modo mais interessante de se abordar a lógica informal é encará-lo não como um substituto da lógica formal (o que se-

\footnotetext{
20 "Unfortunately, there exists by any reasonable standard no respectable general theory of informal argumentation. It serves no constructive purpose to argue in detail for this judgment here. If your intellectual tastes are such that you are satisfied with the theoretical level of traditional rhetorical theories or of so-called theories of informal reasoning, I am not going to be able to re-educate you in half-anhour." p. 4

${ }^{21}$ Segundo sua caracterização, a lógica informal pretende oferecer uma teoria do raciocínio de modo a não reduzi-lo a uma cadeira de inferências dedutivas. A lógica informal, segundo Hintikka, deveria oferecer uma teoria da inferência mais substancial, capaz de elencar e explicitar o conjunto de princípios do raciocínio que nos levam a mudar de crença quando somos apresentados a novas evidências (e não apenas o princípios que nos levam a inferir, de modo válido, que certas crenças se seguem necessariamente dada a verdade de outras). Até então, segundo ele (o artigo é de 1989), a lógica informal ainda não havia apresentado tal teoria da inferência alternativa à dedução. E, do modo como Hintikka interpreta o alcance desejado pela lógica informal, o "movimento" não apresentou uma alternativa desta envergadura até hoje e, penso eu, que nem irá apresentar. Hintikka espera que a lógica informal, para ser bem-sucedida, tenha um alcance igual ou maior que o da lógica formal.
} 
ria impossível) e nem como um estudo sobre procedimentos de maior ou igual alcance que o dos sistemas dedutivos, mas como um esforço de sistematização de modos de argumentar e demonstrar que estão em continuidade com a dedução e que, de uma forma ou outra, a tomam como o modelo de inferência para o raciocínio correto. Assim, se por um lado, Hintikka exige critérios excessivamente rígidos para o bom funcionamento da lógica informal, por outro lado, ele está certo em esperar que ela torne claro seu lugar frente à lógica formal. O desafio posto por Hintikka é, portanto, mostrar que a lógica informal é uma empreitada viável e, ainda que não seja e não venha a ser um substituto da lógica formal, ela não deve ser identificada à falta de rigor e à inutilidade. O presente artigo, ao abordar as noções de método, prova e demonstração, pretende conseguir mostrar que a perspectiva da continuidade entre a lógica formal e a informal é a mais fértil para se compreender a dimensão metodológica da lógica na filosofia.

Sabemos que, se por um lado, não é necessário uma teoria exaustiva da inferência não-dedutiva para o bom funcionamento da lógica informal, por outro, é preciso que a lógica informal se posicione frente a lógica formal já que ela se define por contraste com ela. Além disso, dado que a lógica informal é uma disciplina em construção e tem como objeto argumentos realizados em linguagem natural, a lógica informal carrega consigo características mais próximas da filosofia do que da matemática. Deste modo, a discussão a cerca do melhor critério para se acessar um argumento será sempre dependente de julgamentos que envolvem a ponderação de razões, levando a critérios do tipo “a melhor explicação entre as possíveis”. Juntamente com Johnson (2000) e Haack (1998), considero que a lógica informal e a lógica formal são contínuas e, portanto, complementares. A lógica formal é o estudo de argumentos dedutivamente válidos, ou seja, argumentos em que se as premissas forem verdadeiras, a conclusão se segue necessariamente.

Na lógica formal utilizamos sistemas dedutivos que nos permitem manipular argumentos dedutivamente válidos de alto grau de complexidade a partir de regras de inferência, derivação e transformação (sendo elas mesmas tautologias, teoremas dentro do sistema ou padrões de argumentos dedutiva- 
mente válidos mais simples). A lógica informal, por sua vez, é um esforço de categorização e sistematização de argumentos em linguagem natural que são, em sua maioria, não-dedutivos. A lógica informal propõe um método geral de reconstrução e análise de inferências, mas este método não é um procedimento mecânico capaz de calcular o que se segue do quê, dado um conjunto qualquer de sentenças. Enquanto a lógica formal lida com as inferências que se seguem necessariamente a partir de um conjunto de sentenças supostamente verdadeiras, a lógica informal trata de inferências que se seguem apenas provavelmente a partir de um conjunto de sentenças supostamente verdadeiras. Dado que a lógica formal e informal ambas tratam do estudo e da análise de inferências, não há entre elas uma diferença de natureza, mas de grau de confiabilidade e de grau de certeza no que diz respeito a seus objetos e métodos. Como são ambas os estudos das inferências, lógica formal e lógica informal devem ser consideradas como uma unidade, ainda que cada uma cumpra funções distintas na análise de inferências. Essa unidade se dá porque ambas são análises do raciocínio, estudos do que segue do quê, ou seja, sistematizações de esquemas de inferências bem aceitos. Ainda que empreitadas contínuas, a lógica formal e a informal fazem usos de métodos distintos. Estes métodos, entretanto, são complementares. Para demonstrar sua complementaridade, é preciso mostrar duas coisas: que a lógica formal complementa a lógica informal e que a lógica informal complementa a lógica formal.

A lógica formal complementa a lógica informal porque as linguagens da lógica proposicional e de predicados são fundamentais para a compreensão do que é a relação de inferência correta, para o conhecimento do conceito de derivação e implicação, bem como para o compreensão do que são as regras do raciocínio e as formas lógicas propriamente ditas. A lógica formal é o núcleo duro do estudo das relações de inferência e é a partir dela que outros estudos são desenvolvidos. A lógica informal se beneficia da lógica formal na medida em que a lógica formal oferece os métodos mais fortes e os critérios mais bem-estabelecidos para a análise de inferências. A lógica formal oferece um modelo de funcionamento para a lógica informal, porque nela o método é bem formado quanto os objetos são bem estabelecidos, a ponto de, como vi- 
mos, haver o contra-movimento que considera que apenas a lógica formal oferece uma verdadeira análise de inferências pois as únicas inferências que valem debruçarmo-nos sobre são as dedutivas. Como mostra Seoane (2014) a lógica formal pode nos auxiliar na compreensão da complexidade dos argumentos filosóficos por sua capacidade de expressar a riqueza das relações de inferências a partir do uso da estratégia de tradução e cálculo. Quando é possível utilizar esta estratégia, ela se mostra muito útil:

dado um argumento em linguagem natural, o transformamos (via modelo diádico) em um conjunto de fórmulas de uma linguagem formal lógica e aplicamos a tal conjunto, na melhor das hipóteses, algum algoritmo que permita decidir se ele cumpre ou não uma certa e bem definida propriedade matemática, a partir de tal resultado se pode falar do argumento original em termos de correção/incorreção lógica. (Seoane 2014, p.184)

Mas como Seone mesmo afirma, esta estratégia nem sempre funciona e ela pode ser aplicada de modo débil quando a forçamos sobre argumentos que não permitem uma tal interpretação algorítmica. O que estes argumentos que são irredutíveis à estratégia de tradução nos indicam é que esta estratégia de tradução e cálculo não é o único modo pelo qual a lógica formal colabora com a compreensão de argumentos e que existem outras formas de interação entre lógica formal e os argumentos irredutíveis às formas dedutivamente válidas. Seone defende que há uma grande riqueza de interação entre lógica [formal] e argumentação: "as ferramentas conceituais da teoria lógica [formal] aparecem como um importante guia para resolver, de modo flexível, os problemas particulares de identificação e avaliação e como um importante guia para a reflexão geral a respeito da avaliação do trabalho justificador das premissas." (Seoane 2014, p.185) Assim, compreendemos que a lógica formal cumpre uma função fundamental no estudo e na construção de argumentos. Por outro lado, acreditamos também que é verdadeiro dizer que a lógica formal se beneficia das técnicas e métodos da lógica informal, ou seja, é verdadeiro dizer que a lógica informal complementa a lógica formal.

A lógica informal complementa a lógica formal pois para que ocorra o desenvolvimento da lógica formal, a construção de sistemas dedutivos, de novas lógicas, é preciso que haja um âmbito da experiência demonstrativa ainda 
não formalizado. No contexto da construção ou do aspecto inventivo da lógica, é necessário que ela se debruce sobre aspectos da linguagem e do raciocínio que ainda não foram formalizados. Os esforços de categorização, sistematização e formalização da lógica informal permitem a compreensão das regras não escritas da argumentação. Para que o processo de formalização avance, como por exemplo vemos nos esforços da lógica deôntica, etc, a lógica informal e sua categorização e sistematização de proposições e argumentos fornece material para a lógica formal. Mas isto não quer dizer que a lógica informal só complementa a lógica formal na medida em que ela pode servir de material para formalização. A lógica informal e as análises dos princípios norteadores da argumentação em linguagem natural são importantes também para os debates a respeito dos critérios para avaliação dos sistemas formais bem como para as discussões relativas à natureza destes sistemas. Como nos lembra Kripke ${ }^{22}$ em seu "elementary methodological sermon" de 1976:

As investigações lógicas podem ser obviamente usadas como uma ferramenta útil da filosofia. Elas devem, entretanto, ser acompanhadas pela sensibilidade à significância filosófica do formalismo e por uma dose generosa de senso comum, assim como por um profundo conhecimento tanto dos conceitos básicos quando dos detalhes técnicos do material formal utilizado. Não se pode supor que o formalismo é capaz de forjar resultados filosóficos de uma maneira que ultrapasse o raciocínio filosófico mais básico (ordinary philosophical reasoning). Não existe substituto matemático para a filosofia ${ }^{23} \mathrm{p}$. 416.

\footnotetext{
${ }^{22}$ Nestas páginas finais do artigo, Kripke organiza o debate, a crítica que recebeu e a crítica que realizou em termos de princípios gerais para debates em lógica formal. Estas páginas são preciosas pois ele oferece uma lista de princípios que chama de "elementary methodological morals", elencando os vícios de argumentação da literatura técnica. Estes princípios deveriam ser usados para nortear toda e qualquer discussão que envolva sistemas formais. Aqui os trago os princípios de Kripke como princípios gerais que devem nortear os esforços de definição da lógica informal e seus modos de interação com a lógica formal. Eles são os seguinte: 1) devemos tomar cuidado para não basear uma discussão filosófica em uma falsidade matemática ou em um trivialmente falso "hard logical fact"; 2) é fundamental termos em mente e realizarmos distinções conceituais básicas; 3) filósofos não devem confundir suas doutrinas filosóficas particulares com os resultados básicos e os procedimentos da lógica matemática; 4) a tendência em se propor critérios puramente técnicos com o propósito de se excluir estratégias que não gostamos deve ser reprovada. ("ao menos que à um critério puramente técnico tenha sido dada uma justificativa rigorosamente filosófica que realmente justifique que ele seja adotado à priori,..., é preciso que este critério seja considerado parte de uma hipótese com a qual o autor escolheu trabalhar"); 5) filósofos devem manter-se céticos frente à tentativas fáceis de se resolver questões linguísticas ou empíricas por meio de considerações formais a prior que sejam rápidas demais ("é certamente verdadeiro que alguns autores mais recentes de filosofia são tão apaixonados pela lógica formal que eles escrever como se ela pudesse ser utilizada para resolver questões admitidamente empíricas sobre o Inglês [linguagem natural] sem que se realize o mínimo de trabalho empírico"); 6) filósofos devem ter um senso melhor tanto do poder quanto das limitações das técnicas formais e matemáticas ("um pouco de senso comum é necessário para se manter sob controle a tendência dos filósofos de construir castelos formais imaginários [formal castles in the air]."
} 
Essa afirmação de Kripke vai na direção da conclusão de Pereira no artigo "Brower e A Natureza da Lógica": é preciso não esquecer a máxima tautológica que diz "pensar é pensar, calcular é calcular” (Pereira 2008 p. 979). Confundir cálculo com o pensamento é um erro elementar. E porque partimos do princípio de que o pensar não se reduz ao cálculo, consideramos que a análise geral de argumentos (a lógica informal) nos permite deixar explícitos os princípios da lógica formal e servir como estratégia para o exercício da filosofia em geral e da filosofia da lógica.

Haack (2006) nos oferece mais evidências para o nosso argumento de que a lógica informal complementa a formal ao mostrar que a filosofia da lógica não pode ser plenamente substituída por um procedimento de cálculo sob pena de se perder um âmbito largo e rico de procedimentos de raciocínio que fazem parte do universo das experiências demonstrativas. Dado que a filosofia da lógica se ocupa de âmbitos como, por exemplo, a epistemologia (e a construção de lógicas epistêmicas) e a metafísica (e a identificação dos compromissos ontológicos de um sistema formal), que resistem à regimentação, seu exercício não poder ser realizado unicamente através de procedimentos matemáticos e não poder se reduzir às estratégias de tradução e cálculo ${ }^{24}$. Este fato evidencia que também que há uma diversidade rica de relações entre a lógica informal e a lógica formal.

Os modos de demonstração que nos servirão de parâmetro para nossa investigação sobre as relações entre lógica formal e informal são a dedução

\footnotetext{
${ }^{23}$ Saul Kripke (1976) "Is there a problem with substitutional quantification?" in Evans, G. \& McDowell, J. (orgs.) Truth and Meaning Essays in Semantics. OUP, 1999. p.325-420

${ }^{24}$ Este mesmo problema se estende para a lógica, no contexto das discussões sobre demarcação já que são discutíveis os critérios para se determinar se um sistema formal é ou não uma lógica. Haack nos lembra que Dummet, por exemplo, argumentou em 1973 que as lógicas epistêmicas não são realmente lógicas "porque crença e conhecimento são noções irremediavelmente vagas" (Haack, Filosofias, p.33). Haack, entretanto, propõe que concedamos o benefício da dúvida a respeito do status como lógica de sistemas alternativos ao da lógica clássica. A vantagem do benefício da dúvida é que ela impede a abordagem excessivamente rigorosa e, por vezes dogmática, em relação aos sistemas alternativos. A análise de sistemas alternativos por analogia com a lógica clássica é um procedimento que dá à lógica clássica um status que é filosoficamente problemático, na medida em que ela é tomada como critério indiscutível e como modelo único para se definir o que é a lógica. Ainda que a lógica clássica seja um bom critério e um bom modelo do que deve ser considerado como uma lógica, por outro, este fato não pode levá-la a ser um critério indiscutível ou um que seja tomada como modelo único a priori. Para o benefício da lógica como uma prática, é necessário que seus critérios e modelos possam sempre passar por revisões racionais, nesse sentido é importante que o lugar da lógica clássica como fornecedora de critérios últimos seja colocado em questão.
} 
natural e as suas regras ${ }^{25}$, as provas por indução matemática e o método de análise de argumentos. Dentre os métodos formais de prova ou demonstração, iremos investigar em que medida os sistemas de dedução natural cumprem a motivação que se encontra em suas origens: servir como um sistema que simula as inferências realizadas naturalmente pelo pensamento de modo que suas regras parecem o menos artificial possível. Arthur (2011) nos lembra que "o método de dedução natural tem a vantagem de que está baseado em regras de inferência que refletem muito proximamente as formas com as quais raciocinamos intuitivamente, ou ao menos as regras que estão implícitas em nosso raciocínio" (p.17). Para analisar o caráter intuitivo dos sistemas de dedução natural devemos verificar em que medida as regra de introdução e de eliminação de conectivos segue o uso dos conectivos em linguagem natural e nos argumentos filosóficos na história da filosofia. ${ }^{26}$

Ortiz (2014), por exemplo, aponta o caráter contra-intuitivo da regra de introdução da disjunção, pois ela enfraquece a verdade de uma proposição ao adicionar a ela um disjunto falso. Consideremos o caso proposto por ele: “Antonio sabe hablar español”. Se é verdadeira esta frase, temos que a frase “Antonio sabe hablar español o inglés" também é verdadeira. Entretanto, ao inserimos a disjunção para construir esta segunda frase, acabamos construindo uma afirmação mais fraca. Diferente de Ortiz, considero que há casos retóricos em que a introdução da disjunção funciona perfeitamente para reforçar a verdade de uma afirmação. E isto pode ser visto no exemplo que ele mesmo dá, mas que ele considera também um exemplo de enfraquecimento da afirmação original. O exemplo é o seguinte: "Madrid es la capital de España”. Ortiz (2014) considera que ao adicionarmos um disjunto qualquer, esta afirmação torna-se mais fraca, inclusive o disjunto "yo soy Bruce Lee”. É possível, entretanto, imaginar um caso onde dois interlocutores estão conversando sobre capitais dos países da Europa, nenhum dos dois é, tem o mesmo nome ou se parece com Bruce Lee, mas ambos são fãs do ator. Se neste caso, um

\footnotetext{
25 Os sistemas de dedução natural que nos interessa aqui são os chamados $\mathrm{SD}, \mathrm{SD}+, \mathrm{PD}, \mathrm{PD}+, \mathrm{PDE}$

${ }^{26}$ Nossa análise tem como inspiração de base o puzzle lógico de Peter Wason (1966), o chamado Wason selection task. Wason construiu um puzzle lógico com o qual conseguia avaliar em que medida o uso intuitivo do condicional seguia, acompanhava, o seu uso formal. Outras referências para o tipo de análise do uso de conectivos que apresento aqui são: Sautter (2015) em seu "Compreensão lógica e compreensão cotidiana" e Ortiz (2014) em "Um sistema natural de deducción natural".
} 
deles afirmar que Madri é a capital da Espanha e outro discordar, dizendo que na verdade a capital da Espanha é Barcelona, então, o primeiro poderá, em um movimento retórico bem sucedido, introduzir a disjunção para fins de convencimento. Neste caso, quando ele enuncia: "Madri é a capital da Espanha ou Eu sou o Bruce Lee", a verdade da afirmação original fica mais evidente e mais forte. Assim, podemos ver que, em certos casos, utilizamos sim a introdução da disjunção para facilitar o convencimento.

Outra vantagem de tomar os sistemas de dedução natural como fonte do estudo das noções de inferência, e demonstração, capazes de nos informar sobre as relações entre lógica formal e informal, entre filosófica e lógica, é que este sistema opera com regras que podem ser consideradas elas mesmas tipos específicos de prova. Vejamos alguns exemplos:

Regra de introdução da negação:

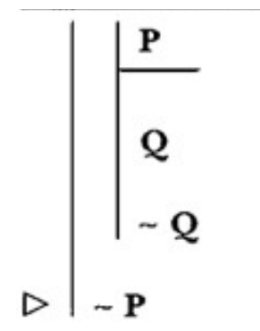

Regra de eliminação da negação:

$$
\left.\right|_{\mathbf{P}} \mid \begin{gathered}
\sim \mathbf{P} \\
\mathbf{Q} \\
\sim \mathbf{Q}
\end{gathered}
$$


Regra de eliminação da disjunção:

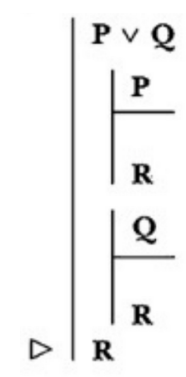

A regra da introdução e da eliminação da negação são, em si mesmas, provas por contradição (ou reductio ad absurdum), ou seja, assumimos que a negação do que queremos demonstrar é verdadeiro. Dela derivamos uma contradição e, portanto, demonstramos que a hipótese de que a negação do que queríamos demonstrar é falsa. A eliminação da disjunção, por sua vez, pode ser apresentada como uma prova por análise de casos. Avaliamos se com o disjunto esquerdo podemos derivar uma sentença $\mathrm{R}$ qualquer. Depois avaliamos se com o disjunto direto podemos também derivar R. Se for o caso que de ambos os disjuntos podemos derivar $\mathrm{R}$, então, podemos derivar $\mathrm{R}$ da disjunção inicial. Todas as derivações nos sistemas de dedução natural funcionam como a regra de introdução do condicional, elas são um raciocínio hipotético no qual partimos das premissas ou dos axiomas e verificamos se podemos chegar à fórmula que tomamos como conclusão. Com a análise destes exemplos prosseguiremos a investigação sobre as relações entre regras de inferência formais e raciocínio informal.

O segundo modo de demonstração que tomaremos como objetos de estudo a fim de analisar as diferenças e semelhanças entre a lógica formal e a lógica informal são as provas por indução matemática como elas aparecem na lógica. Enquanto a dedução natural é uma técnica de manipulação simbólica para realizar demonstrações no interior de um sistema dedutivo, a indução matemática é usada para demonstrar resultados sobre a semântica e a sintática destes sistemas. Por isso, a indução matemática é um modo de demonstração comumente utilizado na metateoria dos sistemas lógicos. O método de indução matemática é uma estratégia que faz uso de definições recursivas e de um 
passo indutivo que, conjuntamente, permitem demonstrar que um resultado vale para um número infinito de itens. Ele funciona para demonstrar metateoremas nos sistemas lógicos porque não só as sentenças formadas são compostos verofuncionais definidos recursivamente como sua construção é fundada no princípio de composicionalidade. Ainda que a indução matemática funcione pela introdução do passo indutivo, não podemos considerá-la como idêntica à a indução empírica. Como diz Max Back (1971): "a indução matemática não é uma forma especial da indução ordinária; ela é uma variedade de prova rigorosa: uma demonstração ou dedução" ${ }^{27}$. Assim, consideramos que as provas por indução matemática constituem um objeto importante para a presente investigação. Tomemos, como exemplo para nossa explicação metodológica, a prova do lema TFI-1 da semântica da lógica sentencial2 ${ }^{28}$ :

(Lema TFI-1): Se $P$ é uma sentença em LS sem nenhum conectivo binário, então $P$ é vero-funcionalmente indeterminado.

A prova deste lema, que é realizada considerando o tamanho da sentença $P$, contém uma cláusula base e um passo indutivo. Vejamos:

Prova: por indução no comprimento de $P$

Passo Base: Suponha que $P$ seja uma sentença negada de forma $\sim P$ de tamanho zero. Então, $P$ é uma sentença atômica, ou seja, $P$ é uma letra sentencial. Agora defina as funções $\mathfrak{A}_{1}$ e $\mathfrak{A}_{2}$ de atribuição de valor de verdade do seguinte modo:

$\mathfrak{A}_{1}(\mathrm{R})=\mathrm{T}$ para todas as letras sentenciais $\mathrm{R}$
$\mathfrak{A}_{2}(\mathrm{R})=\mathrm{F}$ para todas as letras sentenciais $\mathrm{R}$

27 Black, Max em Encyclopedia Americana, vol. 15, 1971. p.100 cf.. Carnielle \& Epstein. "Computabilidade, funções computáveis, lógica e os fundamentos da matemática” Editora UNESP, São Paulo. 2005 p.59.

${ }^{28}$ A prova deste lema, bem como de outros resultados em LS e LP utilizados aqui foram tiradas de Klenk (2002) e Bergman, Moore \& Nelson (2009). 
Ou seja, para cada letra sentencial, podemos aplicar a função $\mathfrak{A}_{1}(\mathrm{R}) \mathrm{ou}$ $\mathfrak{A}_{2}(\mathrm{R})$. Portanto, $\mathfrak{A}_{1}(P)$ é verdadeiro e $P$ é verdadeiro em $\mathfrak{A}_{1}$ e $\mathfrak{A}_{2}(P)$ é falso e $P$ é falso em $\mathfrak{A}_{2}$. Logo, $P$ é vero-funcionalmente indeterminado.

Passo indutivo: Suponha que TFI-1 seja verdadeiro para todo $P$ de tamanho $\mathrm{K}$ ou de tamanho menor que $\mathrm{K}$. Assuma que $P$ é uma sentença negada de forma $\sim P$ de tamanho $\mathrm{K}+1$. Sendo assim, $P$ é uma sentença de forma $\sim \mathrm{Q}$, onde Q é sentença negada de tamanho K. Por nossa hipótese indutiva, Q é vero-funcionalmente indeterminado. Deste modo, há funções de atribuição de valor de verdade $\mathfrak{A}_{3}$ e $\mathfrak{A}_{4}$ de modo que Q é verdadeiro em $\mathfrak{A}_{3}$ e falso em $\mathfrak{H}_{4}$. Assim, $\sim Q$, ou seja, $\mathrm{P}$, é falso em $\mathfrak{A}_{3}$ e verdadeiro em $\mathfrak{A}_{4}$. Portanto, se $P$ é uma sentença de qualquer tamanho, seja 0 , seja $\mathrm{K}$, ou $\mathrm{K}+1$, dado que $\mathrm{P}$ seja uma sentença sem nenhum conectivo binário, então $\mathrm{P}$ é vero-funcionalmente indeterminado.

Esta prova mostra que quando queremos mostrar teses sobre a semântica e a sintaxe de sistemas como a lógica sentencial ou a lógica de predicados de primeira ordem, realizamos raciocínios em linguagem natural. Entretanto, estas provas em linguagem natural tem uma estrutura argumentativa bem formada que é, de certo modo, uma estrutura padrão. Para que a lógica seja analisada sob seu aspecto metodológico, é importante mostrar que a lógica, em um sentido mais largo, não tratar apenas de demonstrações em linguagem simbólica, mas inclui também demonstrações em linguagem natural. Essa é a importância de passarmos pela análise das provas por indução matemática em nosso projeto. Além da prova por indução matemática, outro modo de demonstração que faz uso da linguagem natural é o o método de análise de argumentos. O método de análise de argumentos, no entanto, não faz parte dos procedimentos da lógica formal, mas da prática informal. No método de análise de argumentos os passos de demonstração não são regimentados. Entretanto, os argumentos quando categorizados pelo método de análise, podem ser interpretados a partir de sua semelhança estrutural. O método da análise de 
argumentos é realizado a partir de certos princípios de reconstrução e avaliação. Esta estratégia de análise é utilizada não apenas nas aulas de lógica informal, mas também na construção de argumentos filosóficos, ou seja, ela é recorrente tanto no ensino quanto na pesquisa. A análise de argumentos é uma estratégia formalmente muito simples. Ela é constituída de duas partes: a reconstrução e a avaliação.

A análise ocorre de modo que todo e qualquer argumento, antes de ser avaliado, deve ser reconstruído e colocado em sua forma padrão. A reconstrução de argumento é feita de modo a excluir da avaliação qualquer ruído ou ambiguidade. Na reconstrução também adiciona-se de modo a tornar explícita qualquer premissa fundamental que o autor do argumento tenha deixado implícita. Para tanto, é preciso que se mapeie as sentenças a partir das relações que mantém entre si. De um modo geral, o que isso significa é que diferenciamos premissas, conclusões intermediárias e conclusão final. As premissas são reescritas e encadeadas de modo que o argumento reconstruído em sua forma padrão esteja bem formado. A vantagem da reconstrução é que ela torna argumentos com estrutura complexa mais claros. A simplicidade do método de reconstrução, entretanto, não indica que ele é trivial. O esforço da reconstrução é em deixar claro o papel de cada proposição e sua forma (universal, particular, afirmativa ou negativa), como um passo (análogo à tradução) e que é preparatório para a avaliação (nesse caso, um passo que é análogo ao cálculo).

Há dois princípios que guiam a reconstrução de argumentos: o princípio de caridade e o princípio de fidelidade. Estes princípios são importantes de serem explicitados porque a razão para se reconstruir um argumento não é exatamente refutá-lo ou defendê-lo, mas tornar sua estrutura explícita para melhor compreendê-lo. O propósito da reconstrução é, portanto, produzir um “conjunto de sentenças que representem o argumento real - ou seja, as premissas, a conclusão, e a relação entre as premissas e a conclusão - que o autor procurou apresentar." (Hughes 2015, p.67) Nesta reconstrução, revisamos os termos utilizados pelo autor e os rescrevemos de modo a eliminar ambiguidades e construir um argumento padrão bem formado. Face a uma ambiguidade ou falta de clareza, ao invés de reconstruirmos o argumento de modo que ele 
fique fácil de ser refutado, o tornamos mais claro e mais forte. Assim, o princípio de caridade é importante porque nos força a analisar o argumento em sua forma mais razoável, mais forte possível. A reconstrução caridosa, entretanto, pode levar a excessos. Assim, devemos também atentar para o princípio de fidelidade. Não se deve reconstruir um argumento oferecendo uma versão padrão que viole a intenção do autor (ainda que esta não esteja clara). O argumento reconstruído deve ser consistentes com as intenções do autor e, se adicionarmos premissas que consideramos estar implícitas, estas devem ser razoáveis e não obviamente falsas. Neste momento da análise há também o perigo de se reconstruir o argumento de modo a termos uma validade barata (“cheap validity”), ou seja, ganharmos de modo fácil, por estarmos encarregados da reconstrução das premissas, um argumento dedutivamente válido. Esse é um dos problemas da abordagem dedutivista, pois não é o caso que a reconstrução do argumento como um argumento dedutivamente válido sempre nos dará a versão mais forte e persuasiva do argumento.

A avaliação do argumento exige duas coisas: o mapeamento do tipo de argumento em questão e a crítica informada (teoricamente embasada) das premissas. Falemos primeiro dos princípios e depois dos tipos gerais de argumento (tipificados por Feldman 1999, Morrow \& Weston 2011, Bonevac 1999). Os princípios que regem a avaliação de argumentos guiam toda e qualquer boa crítica filosófica ou científica. São princípios tão gerais e bem estabelecidos que beiram a trivialidade. Estes princípios na verdade são regras gerais que sistematizam toda boa contra-argumentação. Por exemplo: negar a verdade (e demonstrar a falsidade) da conclusão não é aceitável do mesmo modo que aceitar um argumento porque a conclusão é verdadeira não é. A contraargumentação deve ser direcionada a premissas individuais e elas devem ser criticadas de modo específico, a partir de razões substanciais e relevantes para a questão.

A partir deste método que busca encontrar as estruturas gerais dos argumentos e oferecer, posteriormente, um conjunto de regras gerais ou princípios para avaliação deles, foram categorizados diferentes tipos de argumento. Para cada um destes argumentos há uma forma padrão. Estas formas padrão 
podem ser construídas como estruturas de argumentos dedutivos ou não-dedutivos, dependendo do contexto. De todo modo, não há um procedimento mecânico e único para se acessar a estrutura do argumento e muito menos para avaliar a força indutiva de argumentos não-dedutivos. Ou seja, em argumentos não-dedutivos, não há exatamente como medir ou demonstrar qual o grau de certeza com a qual a conclusão se segue das premissas.

O método de análise de argumento não é um procedimento mecânico de tradução ou de cálculo e suas regras pouco tem em comum com as regras de demonstração matemáticas. Por este motivo ele é, dentre os três métodos acima descritos, o que mais se assemelha ao processo pelo qual a análise filosófica ocorre no âmbito da pesquisa contemporânea. Compreender e analisar obras de grandes autores da história da filosofia exige do pesquisador a capacidade de reconstruir os argumentos principais e formular críticas, objeções e defesas. A parte do nosso posicionamento pessoal frente aos textos clássicos é uma dimensão da análise que pode ser facilmente deixada de lado ou feita de modo pouco estruturado. Por isso o estudo da análise de argumentos se mostra fundamental para o exercício da argumentação filosófica. O método de análise de argumentos nos permite reconstruir os argumentos de obras fundamentais na história da filosofia e nos auxilia para a organização sistemática dos tipos de demonstração e os modos como os grandes autores e autoras realizaram sua argumentação filosófica. Entendo que este artigo abre inúmeras questões para serem aprofundadas mais detidamente em outros trabalhos. Mas depois de ter feito uma leitura de sobre-vôo, apresentando criticamente o uso e o fim dos métodos de demonstração informais e formais, penso ter mostrado tanto o papel metodológico da lógica na filosofia como a continuidade entre as formas de demonstração neste contexto.

\section{Referências}

Aristotle. The Complete Works of Aristotle. Jonathan Barnes (ed.) 2 Volumes. Princeton U Press, 1941.

Arthur, R. T. W. Natural Deduction An Introduction to Logic with Real Arguments, a Little History, and Some Humour. Broadview Press, 2011. 
Bergamnn, Moor \& Nelson.The Logic Book. 6th Edition. McGrawHill, 2014.

Bishop-Clark \& Dietz-Uhler. Engaging in the Scholarship of Teaching and Learning: a guide to the process, and how to develop a project from start to finish. Stylus Publishing, 2012.

Blanché, R. \& Dubucs, J. História da Lógica. Edições 70, 1996.

Bonevac, D. Simple Logic. Oxford University Press, 1999.

Boole, G. An Investigation of the Laws of Thought on which are founded the mathematical theories of logic and probabilities. Dover Publications, 1958.

Brunschvicg, L. Les Etapes de La Philosophie Mathematique. University of Michigan Historical Reprint Series- U Michigan Press, 1922.

Cáceres, D.S. G “ La lógica informal como eje para la enseñanza del Taller de Lectura, Reddacción e Iniciación a la investigación documental III” em Revista de Filosofía Universidad Veracruzana. N. 30-21 México. Set 2014 -Marzo 2015 pp. $97-107$

Carnielle \& Epstein. "Computabilidade, funções computáveis, lógica e os fundamentos da matemática” Editora Unesp: 2005 p.59.

Casanave, A. L. (ed.) Symbolic Knowledge from Leibniz to Husserl. College Publications, 2012.

Copi, I. \& Gould, J. (orgs.) Contemporary Readings in Logical Theory. Macmillan, 1967.

Corcoran, John. "Critical Thinking and Pedagogical License". Manuscrito XXII, 109-116. (1999)

"Logic Teaching in the 21st Century." em Revista de Argumentación y Retórica. Universidad de Guadalajara Vol1.N1. 2016

Cozic, M. \& Bonnay, D. (orgs.) Philosophie de la Logique. Conséquence, preuve et vérité. Vrin, 2009.

Dos Santos, Luiz Henrique Lopes. O Olho e o Microscópio. Nau Editora, 2008.

Esquisabel, O. "Representing and Abstracting: An analysis of Leibniz's Concept of Symbolic Knowledge" em Casanave, A.L. (ed.) Symbolic Knowledge from Leibniz to Husserl. College Publications, 2012.

Ewald, William Bragg. From Kant to Hilbert. Volume 1. Oxford University Press, 2007. 
Feldman, R. Reason and Argument. Prentice Hall, 1999.

. "Thinking, Reasoning, and Education," in Harvey Siegel (ed.), $O x$ -

ford Handbook of Philosophy of Education, Oxford: Oxford University Press, 2009.

Frege, G. Lógica e Filosofia da Linguagem. Edusp, 2009.

Grattan-Guinness. "The Mathematical Turn in Logic" in The Handbook of the History of Logic. Volume 3: The Rise of Modern Logic from Leibniz to Frege. Ed. Gabbay \& Woods. Amsterdam: Elsevier, 2004.

Grennan, W. Informal Logic: Issues and Techniques: A proposal for a new system of argument evaluation. McGill-Queen's University Press, 1997.

Groarke, Leo, "Informal Logic", The Stanford Encyclopedia of Philosophy (Spring 2013 Edition), Edward N. Zalta (ed.), URL = <http://plato.stanford.edu/archives/spr2013/entries/logic-informal/>.

Guttenplan, S. The Languages of Logic. Blackwell, 1997.

Haack, S. Filosofias das Lógicas. Editora Unesp, 1998.

Halper, E. “Aristotle's Scientific Method" in Wians \& Polansky (orgs.) Reading Aristotle Argument and Exposition. Brill, 2017.

Hansen, Hans V.,. "Are there methods of informal logic?” in F. Zenker (ed.), Argumentation: Community and Cognition, Proceedings of the 9th Conference of the Ontario Society for the Study of Argumentation, Windsor: CRRAR, 2011.

Hintikka, Jaakko. "The Role of Logic in Argumentation" in The Monist, Vol. 72, No. 1, Logic as a Field of Knowledge (Jan 1989), pp. 3-24

. Knowledge and Belief. An Introduction to the Logic of the Two Notions. Cornell University Press, 1962.

Hodges, W. Logic an introduction to elementary logic. Penguin Books, 2001.

Hughes, Lavery \& Doran. Critical Thinking An Introduction to the Basic Skills. Broadview Press, 2015.

Ishiguro, H. Leibniz's Philosophy of Logic and Language. Cambridge University Press, 1991

Johnson, R. H. "Informal Logic and Deductivism," Studies in Logic, 4(1): 1737., 2011 
. The Rise of Informal Logic, Newport News, VA: Vale Press (1996); Digital edition, University of Windsor: Windsor Studies in Argumentation, 2014.

Kneale \& Kneale. The Development of Logic. Clarendon Press, 2008.

Klenk, Virginia. Understanding Symbolic Logic. Prentice Hall, 2002.

Kripke, S. (1976) "Is there a problem with substitutional quantification?" in Gareth Evans \& John McDowell (orgs.) Truth and Meaning Essays in Semantics. (1999) OUP p.325-420

Naming and Necessity. Blackwell, 1972.

Legris, J. "Between Calculus and Semantic Analysis. Symbolic Knowledge in the Origins of Mathematical Logic" em Casanave, A.L. (ed.) Symbolic Knowledge from Leibniz to Husserl. College Publications, 2012.

Leitão, S. "O lugar da argumentação na construção do conhecimento em sala de aula.” In: Leitão, S.; Damianovic, M. C.a (Org.). Argumentação na escola: o conhecimento em construção.Pontes Editores, 2011, p. 13-46.

Luque, L. "Logic as (Normative) Inference Theory: Formal vs Non-formal theories of inference goodness." in Informal Logic, 28 (4): 315-334.2009

MacFarlane, J. G. What does it mean to say that logic is formal? $328 \mathrm{f}$. Tese (Doutorado em Filosofia). University of Pittsburgh, 2000.

Malpass \& Marfori. The History of Philosophical and Formal Logic. From Aristotle to Tarski. Bloomsbury Academic, 2017.

Mancosu, P. From Brouwer to Hilbert. Oxford University Press, 1998.

Philosophy of Mathematics and Mathematical Practice in the Seventeenth Century. Oxford University Press, 1996.

Maudet, Nicolas \& Fisher, Alec. "Informal Logic and its Implications for Philosophy.” in Informal Logic. 20 (2).2000.

Mortari, C. Introdução à lógica. Ed. Unesp, 2001

Novaes, C. D. Formal Languages in Logic. A Philosophical and Cognitive Analysis. Cambridge University Press, 2012.

Ortiz, H. H. "Un sistema natural de deducción natural" em Revista de Filosofía Universidad Veracruzana. N. 28-29. Set 2013 - Marzo 2014. pp. 23-43 
Patterson, R. Aristotle's Modal Logic. Essence and Entailment in the Organon. Cambridge University Press, 1995.

Pereira, L. C. P. D. \& Wrigley, M. (Org.). Logic, Language and Knowledge: Essays in Honour of Oswaldo Chateaubriand Filho. CLE- UNICAMP, 1999. v. xxii. 573p .

Pereira, L. C. P. D. “ A Natureza da Logica” em Anales de la Academia de Ciencias de Buenos Aires. 1ed. Buenos Aires: Academia Nacional de Ciencias de Buenos Aires, 2008, v. XLI, p. 969-980.

Prawitz D. "Remarks on some approaches to the concept of logical consequence," Synthese, 62: 153-171. 1985.

2006.

Natural Deduction A Proof-Theoretical Study. Dover Publications,

Sautter, F. T. "Compreensão lógica e compreensão cotidiana" em Secco, G. (org.) Epistemologia e Currículo: registros do II Workshop de Filosofia e Ensino. ED.UFRGS, 2016.

Secco, G. \& Pugliese, N. "On How Logic is presented to the Brazilian Student: a critical Analysis" in Teresita de Jesús Mijangos Martínez (Org.). em Anales del Encuentro de Didactica de Lógica - Academia Mexicana de Lógica A.C., V.1, 2016. pp.78-92

Secco, G. D. "Filosofia no Ensino Médio: distinções preliminares para uma didática mínima da lógica” em Controvérsia, V.09, pp.89-102, 2013.

Tarski, Alfred, 1986, "What are Logical Notions," History and Philosophy of Logic, 7: 143-154.

Velasco, Patricia. "Sobre o lugar da argumentação na filosofia como disciplina” em Educação e Filosofia, v. 31, n.61, 2017.

"Argumentação, Pensamento Crítico e Ensino de Filosofia: (im)precisões conceituais.” In: Carvalho, Marcelo; Benedito de Almeida Jr., J. Filosofia e Ensinar Filosofia. Coleção XVI Encontro ANPOF: ANPOF, 2015, p. 224-236.

. Educando para a Argumentação: contribuições do ensino da lógica. Autêntica Editora, 2010.

. "Sobre o Lugar da Lógica na Sala de Aula" em Revista Sul-Americana de Filosofia e Educação. n.13, 2009.

Villareal, A. C. "Competencia en didáctica de la lógica" em Revista de Filosofía Universidad Veracruzana. N. 17 México. Set. 2005. pp. 37-47 
Perspectiva Filosófica, vol. 47, n. 2, 2020

Wohlrapp, Harald R. The Concept of Argument. A philosophical foundation. Dordrecht: Springer. 2014.

Woods, J. "The Necessity of Formalism in Informal Logic" in Argumentation 3, 1989. 